\title{
Dietary supplements: a great menace of our time or golden remedy? A cross-sectional study among school-aged children
}

\author{
Marta Krawiec ${ }^{1}$, Julita Chadzynska1, Filip Raciborski², Grazyna Kraj', Anna Klak², Boleslaw Samolinski², Marek Kulus ${ }^{1}$ \\ 'Department of Paediatric Pneumonology and Allergy, Medical University of Warsaw, Warsaw, Poland \\ ${ }^{2}$ Department of Prevention of Environmental Hazards and Allergology, Medical University of Warsaw, Warsaw, Poland \\ Adv Dermatol Allergol 2019; XXXVI (6): 681-686 \\ DOI: https://doi.org/10.5114/ada.2019.91418
}

\begin{abstract}
Introduction: Dietary supplements (DS) are commonly used as a remedy for various health issues as they are widely advertised and available.

Aim: This study aimed to evaluate the prevalence of DS use among school-aged children in Warsaw, the capital city of Poland. Additionally, we evaluated the parents' motivations for DS administration, the frequency of the use of specific compounds and the influence of child's history of allergy on DS use.

Material and methods: Children aged 6-7 years who attended the first grade of primary schools in Warsaw were included into the study. Forty-two out of 170 primary schools in Warsaw were randomly selected of which 38 agreed to participate. The research tool was a self-administered questionnaire.

Results: Half of the studied children received DS in the previous 6 months. Fatty acids were the most commonly administered DS (49.8\%). The most common reason for administering DS was prevention of diseases (69.1\%). The total household income correlated positively with the DS use. History of food allergy was one of the factors which increased the risk of DS use, whereas diagnosis of asthma did not correlate with a higher frequency of DS use. Conclusions: This study shows the need to educate patients about medical indications for DS use and expected benefits in the specific indications.
\end{abstract}

Key words: disease prevention, fatty acids, multivitamin, recurrent infections.

\section{Introduction}

According to the Food and Drug Administration definition, a supplement is a dietary ingredient which may be one or any combination of the following substances: a vitamin, a mineral, an amino acid, a herb or other botanical. The definition includes any dietary substance which is used by people to provide essential nutrients [1].

Dietary supplements (DS) industry is expanding rapidly in the developed countries. In the USA, the National Health and Nutrition Examination Survey (NHANES) recorded an increase in the prevalence rate of DS intake from $23 \%$ in 1971-1975 up to 52\% in 1999-2000 [2, 3]. A similar trend was observed in the German population, where the frequency of DS intake reached 36\% in 1994 [4].

In Poland, the market for DS exceeded EUR 400 million in 2010 [5]. According to the data of the Central Statistical Office of Poland, in 2009, 50\% of the studied children received over-the-counter medications and in
$82 \%$ of these cases, DS were the administered pharmaceutical [6].

Despite the popularity of DS consumption, the scientific evidence does not confirm their expected effectiveness [7-11].

Experts' recommendations on DS use in the paediatric population focus on supplementation of specific ingredients only and indicate precisely groups of children at risk of their deficiencies [12].

The DS use in children seems to be exceeding recommendations. However, data concerning the prevalence of DS use in children are scarce.

\section{Aim}

The aim of the study was to examine the prevalence, the parents' motives of DS use and the frequency of the use of specific compounds among the population of the first graders of primary schools in Warsaw.

Address for correspondence: Julita Chadzynska, Department of Paediatric Pneumonology and Allergy, Medical University of Warsaw, 63A Zwirki i Wigury St, 02-091 Warsaw, Poland, phone/fax: +48 2231794 19, e-mail: julita.chadzynska@wum.edu.pl Received: 9.08.2017, accepted: 11.07.2018. 


\section{Material and methods}

\section{Model of the study}

DS use was assessed as a part of a larger project investigating nutrition patterns and food allergy in school children. It was a survey study coordinated by the Department of Prevention of Environmental Hazards and Allergy of the Medical University of Warsaw and implemented after acceptance of local authorities.

The target group was children aged 6-7 years attending the first grade of primary schools in Warsaw.

The study used a representative sample selection. Fortytwo out of 170 primary schools in Warsaw were randomly selected of which 38 agreed to participate. After acceptance of school authorities, parents or caregivers of all first graders were provided with a questionnaire and a cover letter explaining the goals of the study and contact data in case of further questions.

The study was anonymous. Respondents were identified solely on the basis of the ID number assigned for the purpose of the study. The study was conducted in January 2012.

\section{Questionnaire}

The research tool was a self-administered questionnaire, consisting of 58 self-report questions. The questionnaire was prepared using the International Study of Asthma and Allergies in Childhood (ISAAC) and European Community Respiratory Health Survey (ECRHSII) questionnaires [13, 14], both validated in Poland for the purpose of the ECAP (Epidemiology of Allergic Disorders in Poland) Study [12].

Twelve multiple choice questions addressed the problem of DS use. More than one response was possible in the questions concerning the motivation for DS use and type of DS.

Since the term "dietary supplement" could be incomprehensible to some respondents, the questionnaire provided its simple definition.

The frequency of DS use was defined as regular $(\geq 3$ times a week) or occasional (< 3 times a week).

DS were divided into the following groups: 1) single vitamins (e.g. vitamin A, B, C, D, E, folic acid), 2) multivitamin products, 3) minerals (iron, calcium, magnesium, zinc), 4) products containing minerals and vitamins (several popular brand names of products were listed as an example), 5) unsaturated fatty acids (cod-liver oil, DHA products), 6) Vitamin C, 7) probiotics, 8) plants' extracts (garlic, Aloe Vera, Echinacea, choke berry), and 9) others.

Basic demographic data such as age and sex of children as well as information on parents' age, educational and economic status were collected.

\section{Statistical analysis}

A $\chi^{2}$ test or Fisher's exact test (for small sample sizes) were used in the statistical analysis. The $\chi^{2}$ statistics were calculated to determine the strength of association and dependence between variables. Results were considered to be statistically significant at $p<0.05$.

\section{Results}

A total of 3400 questionnaires were issued and 1928 of them were completed and returned. 1758 complete questionnaires were included for further analysis after verification (response rate: $51 \%$ ). Boys constituted $46 \%$ and girls $54 \%$ of the analysed group.

$51.1 \%$ of the surveyed parents declared that their child received DS during preceding 6 months. Among them, $40.1 \%$ administered DS on a regular basis and $59.9 \%$ occasionally.

The characteristics of the study population and influence of specific factors on DS use are presented in Table 1.

Parents' evaluation of the child's health had a significant influence on the decision about supplementation. The parents who assessed their child's health as very good, were less likely to administer DS to their children comparing to other parents ( $p<0.001)$.

Self-assessment of the financial situation of the family did not significantly influence DS use in children. However, there was a significant positive correlation between the total income of the family and DS use $(p<0.005)$.

An association between the history of food allergy in a child and DS administration was observed. The children who were allergic to food antigens received DS more commonly. A positive correlation was seen in subjects with allergy diagnosed by a physician as well as in children reported as allergic by parents alone $(p<0.001)$.

As far as inhalant allergy is concerned, children with doctor's diagnosis of asthma were not found to be receiving DS more commonly ( $p=0.061)$. However, children regarded by parents as allergic to dander or pollen/dust received DS more frequently $(p<0.01$ and $p<0.005$, respectively).

Fatty acids were the most commonly administered DS (49.8\%). The prevalence of the use of specific formulations is presented in Figure 1.

Respondents declared different motives for the administration of DS (Figure 2). The most commonly identified reason was prevention of diseases. Surprisingly only $3 \%$ of parents declared the will of vaccinating their children against influenza.

Reasons such as attention deficit (3.9\%), poor laboratory tests' results (2\%) and decreased activity (1.6\%) formed all together $7.5 \%$ of the answers only and were not presented on the diagram.

$19.8 \%$ of the studied population used DS because of doctor's recommendation, within this group, 30.1\% used DS occasionally and $44.4 \%$ on a regular basis.

The parental assessment of DS effectiveness is presented in Figure 3. 
Table 1. The influence of specific factors on the administration of DS. Data do not sum up to 1758 due to item missing data

\begin{tabular}{|c|c|c|c|c|c|}
\hline \multirow[t]{2}{*}{ Parameter } & \multicolumn{4}{|c|}{ DS use } & \multirow{2}{*}{$\begin{array}{c}\text { Significance } \\
(p)\end{array}$} \\
\hline & $\begin{array}{c}\text { Non-users } \\
n(\%)\end{array}$ & $\begin{array}{c}\text { Occasional users } \\
n(\%)\end{array}$ & $\begin{array}{c}\text { Regular users } \\
n(\%)\end{array}$ & Total & \\
\hline \multicolumn{6}{|l|}{ Child's sex: } \\
\hline Boy & $397(49.7)$ & $229(28.7)$ & $172(21.6)$ & 798 & \multirow[t]{2}{*}{0.408} \\
\hline Girl & $450(48.1)$ & $296(31.6)$ & $190(20.3)$ & 936 & \\
\hline \multicolumn{6}{|c|}{ Self-evaluation of the economic condition of the family: } \\
\hline Very bad & $6(60.0)$ & $2(20.0)$ & $2(20.0)$ & 10 & \multirow[t]{5}{*}{0.474} \\
\hline Bad & $44(53.0)$ & $23(27.7)$ & $16(19.3)$ & 83 & \\
\hline Moderate & $383(50.4)$ & $224(29.5)$ & $153(20.1)$ & 760 & \\
\hline Good & $346(44.9)$ & $250(32.5)$ & $174(22.6)$ & 770 & \\
\hline Very good & $26(56.5)$ & $11(23.9)$ & $9(19.6)$ & 46 & \\
\hline \multicolumn{6}{|c|}{ Household income per month: } \\
\hline Refused to answer & $114(50.0)$ & $62(27.2)$ & $52(22.8)$ & 228 & \multirow[t]{5}{*}{$<0.005$} \\
\hline Less than EUR 600 & $162(58.7)$ & $61(22.1)$ & $53(19.2)$ & 276 & \\
\hline EUR 600 to 1000 & $168(52.7)$ & $98(30.7)$ & $53(16.6)$ & 319 & \\
\hline EUR 1000 to 1500 & $231(45.0)$ & $170(33.1)$ & $112(21.9)$ & 513 & \\
\hline More than EUR 1500 & $175(43.5)$ & $135(33.6)$ & $92(22.9)$ & 402 & \\
\hline \multicolumn{6}{|c|}{ Overall perception of child's health: } \\
\hline Excellent & $362(57.3)$ & $172(27.2)$ & $98(15.5)$ & 632 & \multirow[t]{5}{*}{$<0.001$} \\
\hline Good & $388(41.0)$ & $328(34.7)$ & $230(24.3)$ & 946 & \\
\hline Neither good nor bad & $66(44.4)$ & $30(20.1)$ & $53(35.5)$ & 149 & \\
\hline $\mathrm{Bad}$ & $1(11.0)$ & $4(44.5)$ & $4(44.5)$ & 9 & \\
\hline Very bad & $1(33.3)$ & 0 & $2(66.7)$ & 3 & \\
\hline \multicolumn{6}{|c|}{ Symptoms of food allergy within the latest 12 months: } \\
\hline Yes & $167(38.4)$ & $157(36.1)$ & $111(25.5)$ & 435 & \multirow[t]{2}{*}{$<0.001$} \\
\hline No & $636(52.0)$ & $349(28.5)$ & $238(19.5)$ & 1223 & \\
\hline \multicolumn{6}{|c|}{ Diagnosis of food allergy made by a physician: } \\
\hline Yes & $203(39.4)$ & $178(34.6)$ & $134(26.0)$ & 515 & \multirow[t]{2}{*}{$<0.001$} \\
\hline No & $634(53.0)$ & $342(28.6)$ & $221(18.4)$ & 1197 & \\
\hline \multicolumn{6}{|c|}{ Diagnosis of asthma made by a physician: } \\
\hline Yes & $45(39.1)$ & $38(33.1)$ & $32(27.8)$ & 115 & \multirow[t]{2}{*}{0.061} \\
\hline No & $799(49.8)$ & $476(29.7)$ & $329(20.5)$ & 1604 & \\
\hline \multicolumn{6}{|c|}{ Asthma and allergy signs present on exposure to animals: } \\
\hline Yes & $46(35.4)$ & $49(37.7)$ & $35(26.9)$ & 130 & \multirow[t]{2}{*}{$<0.01$} \\
\hline No & $793(50.0)$ & $469(29.6)$ & $324(20.4)$ & 1586 & \\
\hline \multicolumn{6}{|c|}{ Asthma and allergy signs present when exposed to pollens and dust: } \\
\hline Yes & $124(39.5)$ & $108(34.4)$ & $82(26.1)$ & 314 & \multirow[t]{2}{*}{$<0.005$} \\
\hline No & $711(50.9)$ & $409(29.3)$ & $276(19.8)$ & 1396 & \\
\hline
\end{tabular}

In the group of children who received DS on a regular basis, $70.1 \%$ of parents confirmed their effectiveness, whereas in the group using DS occasionally, $46.0 \%$ expressed the same opinion.
A negative opinion about DS (lack of effect) was expressed by $5.6 \%$ of parents who administered DS regularly and $10.6 \%$ in the group which administered DS occasionally. 


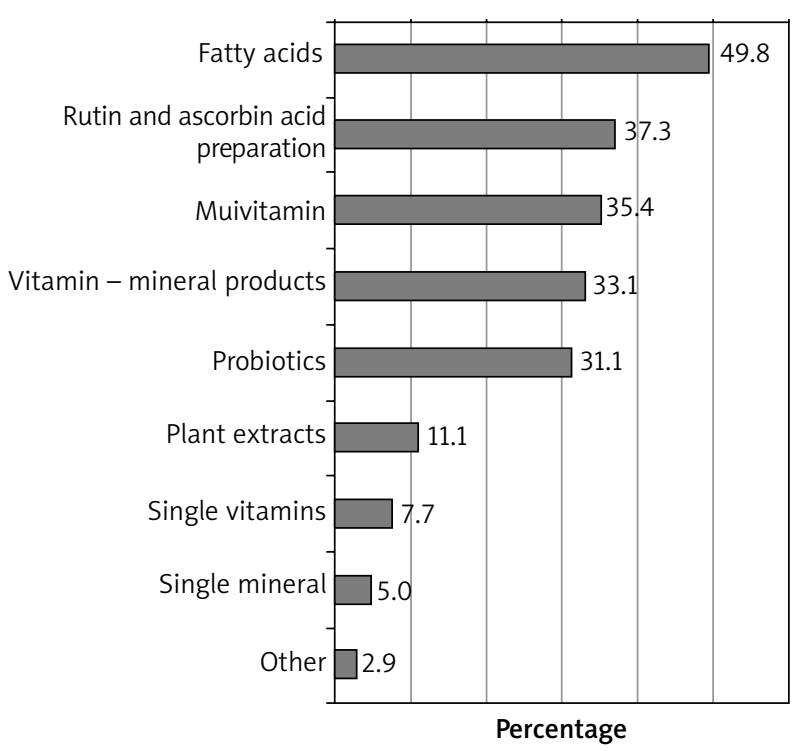

Figure 1. Frequency of use of the particular DS preparations among study population. Percentages do not add up to $100 \%$ due to potential multiple choices

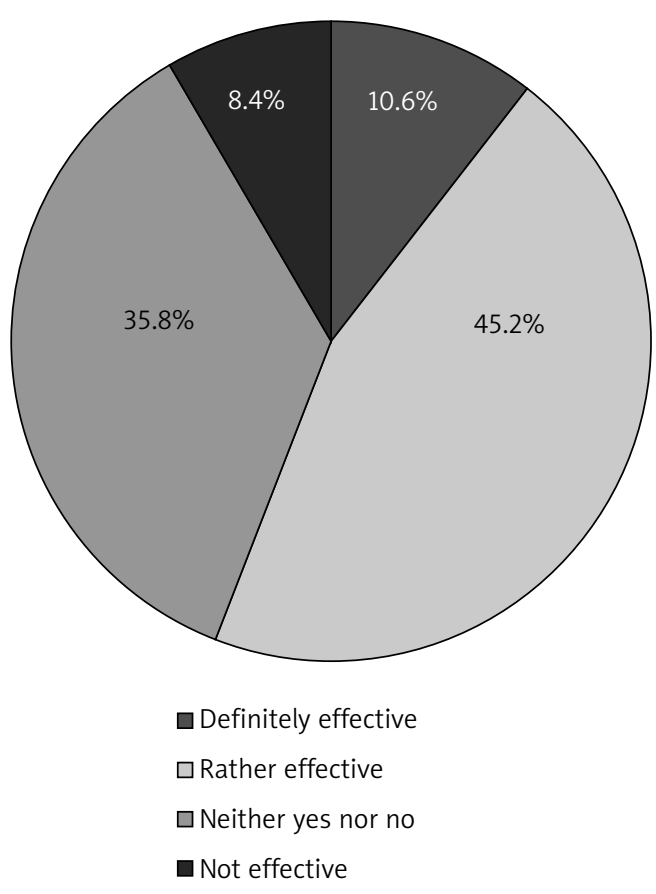

Figure 3. Parental evaluation of DS effectiveness

\section{Discussion}

The results of this survey study of almost 1800 respondents demonstrated that half of first graders in the capital city of Poland used DS in the preceding 6 months. Fatty acids were the most commonly used DS. DS were mainly used for prophylactic reasons.

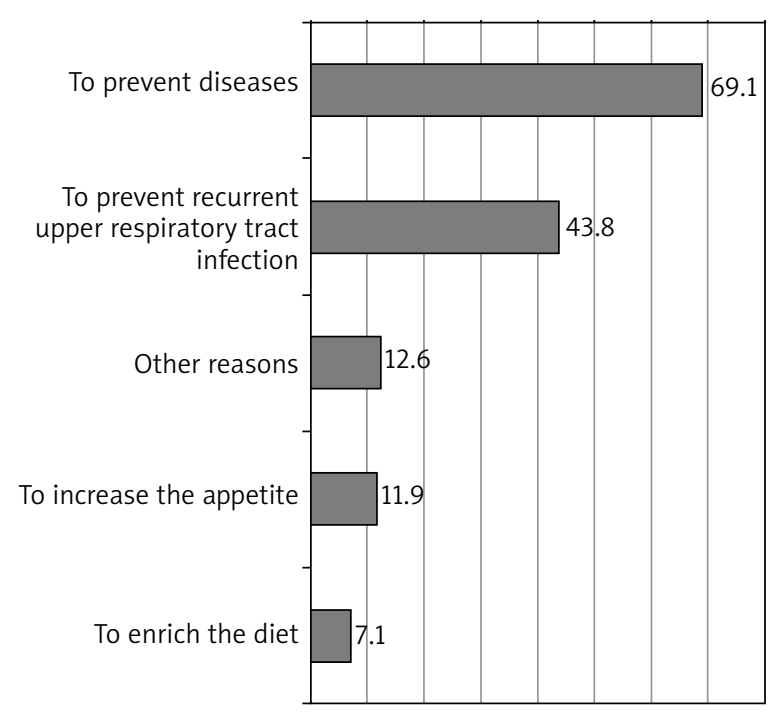

Figure 2. Motivations for DS use. Percentages do not add up to $100 \%$ due to potential multiple choices

\section{Strengths of the study}

The respondents were selected randomly. The sample size was sufficient and homogenous in terms of age and inhabitancy. The response rate was high which increased credibility of the results. Thus, the study reflects reliably the DS use habits in this selected group.

The selection of distractors concerning the use of specific DS was accurate. Only 3\% of the respondents used DS other than the ones listed in our questionnaire. Also the motivations listed in the questionnaire agreed with reasoning of the majority of the parents (only 12.6\% used the distractor "other than listed above").

\section{Limitations of the study}

The study was performed in the capital city of Poland, Warsaw. The medium income and the education level in Warsaw are higher comparing to other regions of the country. Therefore, these results should not be adapted to the general population at this age.

The study was conducted as a self-administered questionnaire survey rather than an interview survey.

\section{Comparison with other studies \\ Prevalence of DS use}

There is a shortage of data on the DS use in this precise age group.

According to results of NHANES from 1999 to 2004, $34.2 \%$ of parents in the USA administered DS to their child in the preceding month [15].

Surprisingly, another health survey in the US population revealed the DS use in the preceding year as low as 
$3.4 \%$ in children aged $4-8$ years. In the same study, adult use of DS reached the level of $17.4 \%$ [16].

A Korean survey from 2012 reported the prevalence of DS use in the preceding month at the level of $45 \%$ in children aged 1 to 6 years [17].

As far as the European population is concerned, the DONALD Study evaluated the DS use in children aged 2 to 18 years as $25.8 \%$.

\section{Motives for DS administration}

The main reason to administer DS in our study was to prevent diseases. Similar results were presented by Bailey et al. who reported an improvement in health and health maintenance as the crucial motivation for DS use in the US population [18]. To upgrade health was also the important reason for DS use in the Korean population [9].

Prevention of respiratory tract infections was the second most important reason for DS use in the studied population. The fact that the study was performed in January, the middle of the infection season in Europe, might have influenced these results. Whereas in a study by Wu et al. [16] DS were used to treat (not to prevent) head and chest cold in the first place.

We aimed to evaluate simultaneous use of DS and influenza vaccination as infection prevention. However, the small size of the vaccinated group (3 children only) made the analysis impossible.

Surprisingly, the attention deficit, which made the second most important reason for DS use in children in the study performed by Wu et al. [16] was indicated as a motivation by only 3.9\% of parents in our population.

Poor appetite was the third most commonly indicated reason in our study. This motive was not identified in other epidemiological studies on the subject.

\section{Characteristics of the population which uses DS}

Our study found a positive association between the administration of DS to children in families with a higher income. A similar association was noticed in the Korean population as well as the Finnish population [19, 20].

Various factors describe the group of DS users among different countries. In the study from the US, first-born children were the ones who received DS more frequently [21]. A Later study performed in the US revealed that greater physical activity and less time spent watching television or playing computer games were positively correlated with multivitamin and multi-mineral supplementation [15].

The DONALD study pointed that a higher education level, working mother, families consisting of more than 3 members, non-smoking family members were the features of the families which were more likely to be DS users [4].

Furthermore, Korean research revealed that children who attended day-care centres, children of mothers who were over 40 years old, children of mothers who used DS themselves and older children were administered DS more commonly [17].

Food allergy in the child was connected with DS administration more commonly. The possible reason may be the suspicion of dietary deficits. Research on nutrients deficiency in children who are on elimination diets because of food allergy is scarce. Experts agree that this group of children needs special attention, screening and counselling about possible dietary deficits [22].

\section{Commonly used DS}

The use of specific DS varies among studies performed in different countries. National guidelines on supplementation of different compounds seem to influence higher intake frequency.

In our study, we recorded the highest intake of omega-3 fatty acids. In Poland omega-3 fatty acids supplementation is recommended in children under 3 years old who do not eat fish regularly. Our results may indicate that parents continue the supplementation in their children up to the school age.

In Germany multivitamin-mineral combinations are administered predominantly in the population of children. The most commonly used single nutrient supplement is fluorine (Donald). The German guidelines recommend the dose of $0.25 \mathrm{mg} / \mathrm{kg}$ of fluorine to prevent caries in children under the age of 3 , what explains an especially high prevalence of fluorine intake among the children between the age 2 and 4 (22-48\%). The administration of fluorine declines above the age of 10 to $2-5 \%$.

According to the study performed by Wang et al., which included children aged 4-17, the most commonly used DS was Echinacea purpura and fish oil [16]. In the Korean population of preschool children, vitamin and mineral supplements were used most commonly (77.5\%), followed by ginseng (49.3\%) and probiotics (62.2\%) [17].

\section{Conclusions}

Despite scarce data on DS effectiveness and safety, half of the first graders in Warsaw use DS, most of them without any doctor's recommendations.

The second most frequently recorded reason for DS intake in children are recurrent infections which indicates a common need for effective remedy for this widespread health issue in children. However, it does not correlate with the increased use of a verified method, such as influenza vaccination.

In children with food allergy, DS are used more frequently which might be caused by parents' fear of nutritional deficiencies in children.

The demonstrated results revealed that DS are frequently used as a remedy in indications in which their efficacy has not been proven. 


\section{Conflict of interest}

The authors declare no conflict of interest.

\section{References}

1. FDA. Dietary supplements Internet: U.S. Food and Drug Administration; 2015 [cited 201613 January]. Available from: http://www.fda.gov/AboutFDA/Transparency/Basics/ ucm195635.htm.

2. Block G, Cox C, Madans J, et al. Vitamin supplement use, by demographic characteristics. Am J Epidemiol 1988; 127: 297-309.

3. Radimer K, Bindewald B, Hughes J, et al. Dietary supplement use by US adults: data from the National Health and Nutrition Examination Survey, 1999-2000. Am J Epidemiology 2004; 160: 339-49.

4. Sichert-Hellert W, Kersting M. Vitamin and mineral supplements use in German children and adolescents between 1986 and 2003: results of the DONALD Study. Ann Nutr Metab 2004; 48: 414-9.

5. Stawarska A. Rynek suplementów diety w Polsce w 2010 r. przekroczy 2 mld zt Internet: PMR Publications; 2009 [cited 201613 January]. Available from: http://inwestycje.pl/rynek zdrowia/Rynek-suplementow-diety-w-Polsce-w-2010-r.-przekroczy-2-mld-zl;53319;0.html.

6. Piekarzewska M, Zajkowska-Kozłowska A. Stan zdrowia ludności Polski w 2009. Internet [cited 201613 January]. Available from: stat.gov.pl/obszary-tematyczne/zdrowie/ stan-zdrowia-ludności-polski-w-2009-r,6,5.html.

7. Fortmann SP, Burda BU, Senger CA, et al. Vitamin and mineral supplements in the primary prevention of cardiovascular disease and cancer: an updated systematic evidence review for the U.S. Preventive Services Task Force. Ann Intern Med 2013; 159: 824-34.

8. Guallar E, Stranges S, Mulrow C, et al. Enough is enough: stop wasting money on vitamin and mineral supplements. Ann Intern Med 2013; 159: 850-1.

9. Tan ML, Ho JJ, Teh KH. Polyunsaturated fatty acids (PUFAs) for children with specific learning disorders. The Cochrane Database Syst Rev 2012; 12: CD009398.

10. Huang HY, Caballero B, Chang S, et al. The efficacy and safety of multivitamin and mineral supplement use to prevent cancer and chronic disease in adults: a systematic review for a National Institutes of Health state-of-the-science conference. Ann Intern Med 2006; 145: 372-85.

11. Feleszko W, Ruszczynski M, Zalewski BM. Non-specific immune stimulation in respiratory tract infections. Separating the wheat from the chaff. Paediatr Respir Rev 2014; 15: 200-6.

12. Holick MF, Binkley NC, Bischoff-Ferrari HA, et al. Evaluation, treatment, and prevention of vitamin D deficiency: an Endocrine Society clinical practice guideline. J Clin Endocrinol Metab 2011; 96: 1911-30.

13. Asher MI, Keil U, Anderson HR, et al. International Study of Asthma and Allergies in Childhood (ISAAC): rationale and methods. Eur Respir J 1995; 8: 483-91.

14. Burney PG, Luczynska C, Chinn S, Jarvis D. The European Community Respiratory Health Survey. Eur Respir J 1994; 7: 954-60.

15. Shaikh U, Byrd RS, Auinger P. Vitamin and mineral supplement use by children and adolescents in the 1999-2004 National Health and Nutrition Examination Survey: relationship with nutrition, food security, physical activity, and health care access. Arch Pediatr Adolesc Med 2009; 163: 150-7.

16. Wu CH, Wang CC, Kennedy J. The prevalence of herb and dietary supplement use among children and adolescents in the United States: results from the 2007 National Health Interview Survey. Complement Ther Med 2013; 21: 358-63.

17. Kim HS, Lee HY, Kim MK. Dietary supplements use and related factors of preschoolers in 3 korean cities. Pediatr Gastroenterol Hepatol Nutr 2013; 16: 104-15.

18. Bailey RL, Gahche JJ, Thomas PR, Dwyer JT. Why US children use dietary supplements. Pediatr Res 2013; 74: 737-41.

19. Kang DS, Lee KS. The status of dietary supplements intake in Korean preschool children: data from the Korea national health and nutrition examination survey 2010-2012. Pediatr Gastroenterol Hepatol Nutr 2014; 17: 178-85.

20. Hameen-Anttila KP, Niskala UR, Siponen SM, Ahonen RS. The use of complementary and alternative medicine products in preceding two days among Finnish parents - a population survey. BMC Complement Altern Med 2011; 11: 107.

21. Rock CL. Multivitamin-multimineral supplements: who uses them? Am J Clin Nutr 2007; 85: 277s-9s.

22. Groetch M, Henry M, Feuling MB, Kim J. Guidance for the nutrition management of gastrointestinal allergy in pediatrics. J Allergy Clin Immunol Prac 2013; 1: 323-31. 